PHYSICAL REVIEW A 93, 049901(E) (2016)

\title{
Erratum: Strongly interacting mesoscopic systems of anyons in one dimension
} [Phys. Rev. A 92, 063634 (2015)]

\section{N. T. Zinner}

(Received 25 March 2016; published 11 April 2016)

DOI: 10.1103/PhysRevA.93.049901

There is a missing term related to the $a_{3}$ coefficient in Eq. (A3) in the Appendix of the paper. The correct equation reads

$$
K=K_{0} \frac{\left(a_{1}-a_{2}\right)^{2}+\left(a_{2}-a_{3}\right)^{2}+\left(a_{1}^{2}+a_{3}^{2}\right)\left|1-e^{-i \theta}\right|}{a_{1}^{2}+a_{2}^{2}+a_{3}^{2}} .
$$

This misprint does not affect any of the results, discussion, or conclusions of the paper. 